Acta Crystallographica Section C

Crystal Structure

Communications

ISSN 0108-2701

\section{A dynamic disorder-linked reversible phase transition in a new chloroform solvate of cis-dichloridobis(triethyl- phosphane)platinum(II)}

\author{
Keith B. Dillon, ${ }^{a}$ Judith A. K. Howard, ${ }^{a}$ Philippa K. \\ Monks, ${ }^{a}$ Michael R. Probert ${ }^{\mathrm{a} *}$ and Helena J. Shepherd ${ }^{\mathrm{b}}$
}

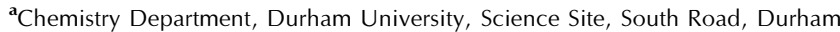
DH1 3LE, England, and ${ }^{\mathbf{b}}$ Laboratoire de Chimie de Coordination, CNRS UPR8241, F-31077 Toulouse, France

Correspondence e-mail: m.r.probert@durham.ac.uk

Received 18 January 2011

Accepted 4 March 2011

Online 10 March 2011

The title compound, cis-dichloridobis(triethylphosphane)platinum(II) chloroform monosolvate, $\left[\mathrm{PtCl}_{2}\left(\mathrm{C}_{6} \mathrm{H}_{15} \mathrm{P}\right)_{2}\right] \cdot-$ $\mathrm{CHCl}_{3}$, has been obtained from ligand scrambling in the cis$\left[\mathrm{PtCl}_{2}\left(\mathrm{Cyp}_{2} \mathrm{PCl}\right)\left(\mathrm{PEt}_{3}\right)\right](\mathrm{Cyp}=$ cyclopentyl $)$ system in $\mathrm{CHCl}_{3}$ solvent. Unlike the two previously reported unsolvated polymorphs, which are both monoclinic, the compound crystallizes in an orthorhombic setting. Furthermore, the system exhibits a reversible temperature-dependent structural phase transition, coupling a reduction in anisotropic displacement parameters and a reduction in crystallographic symmetry on cooling. The high-temperature phase adopts space group Pnma with the complex and solvent molecules sitting across a crystallographic mirror plane $\left(Z^{\prime}=0.5\right)$. The low-temperature phase adopts the space group $P 2_{1} 2_{1} 2_{1}$ with $Z^{\prime}=1$.

\section{Comment}

As part of our studies on hydrolysis/hydroxylation of chlorophosphane ligands in situ on platinum(II) centres (Cornet et al., 2011), we have prepared in solution the complex cis$\left[\mathrm{PtCl}_{2}\left(\mathrm{Cyp}_{2} \mathrm{PCl}\right)\left(\mathrm{PEt}_{3}\right)\right](\mathrm{Cyp}=$ cyclopentyl $)$ and allowed it to hydrolyse slowly by exposure to air. During the hydrolysis process, however, the ${ }^{31} \mathrm{P}$ NMR solution-state spectra of the reaction mixture demonstrated that ligand scrambling was occurring. Crystals suitable for single-crystal X-ray diffraction were isolated from the reaction mixture which proved to be a new 1:1 solvate of cis- $\left[\mathrm{PtCl}_{2}\left(\mathrm{PEt}_{3}\right)_{2}\right]$ with $\mathrm{CHCl}_{3}$, (1).

Analysis of the variation of the length of the crystallographic $c$ axis of (1) with temperature (Fig. 1) clearly demonstrates the onset of a phase transition at $149 \mathrm{~K}$. Data for the calculation of these unit-cell parameters were collected during continuous very slow cooling $\left(2 \mathrm{~K} \mathrm{~h}^{-1}\right)$; the data collections were such that equal amounts of reciprocal space were sampled for each data point, with the temperature of the data point being assigned to that at the mid-point of the scan. Each point on the graph therefore represents data recorded over $1 \mathrm{~K}$. Full data collections and structural determinations were then carried out above and below the phase-transition temperature at $220 \mathrm{~K},(1 a)$, and $120 \mathrm{~K},(1 b)$, respectively.

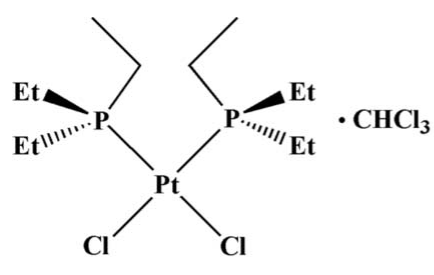

$(1 a) /(1 b)$

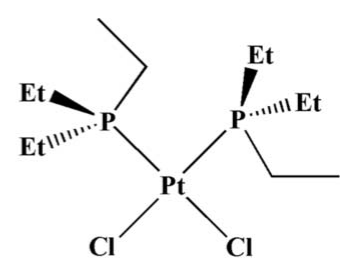

(2)
At $220 \mathrm{~K}$, the space group of the solvated complex, $(1 a)$, is Pnma, with a mirror plane bisecting both the Pt complex and the solvent molecule, resulting in a structure with $Z^{\prime}=0.5$. The $\mathrm{CHCl}_{3}$ molecule shows dynamic disorder, rotating about the $\mathrm{C}-\mathrm{H}$ bond axis in a symmetrical fashion with respect to the mirror plane.

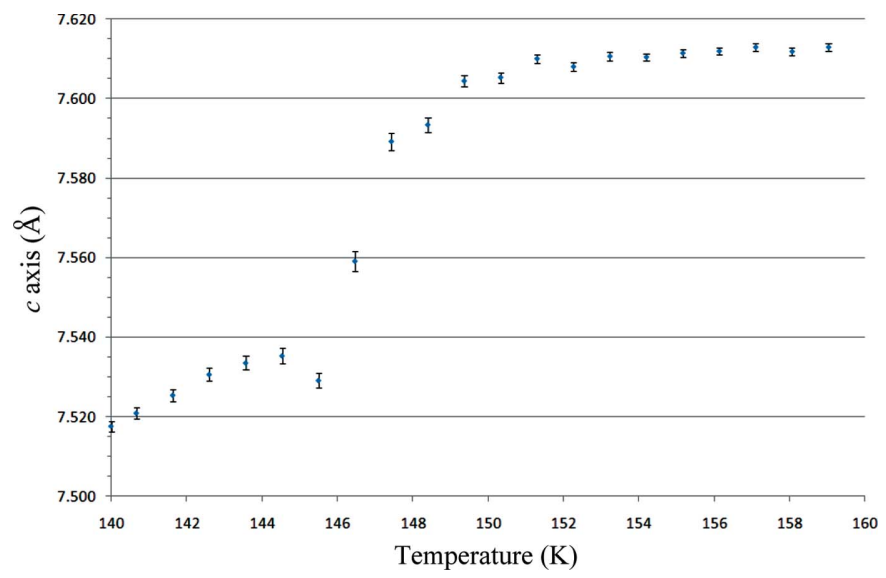

Figure 1

Graph showing the evolution of the $c$-axis length of (1) with temperature.
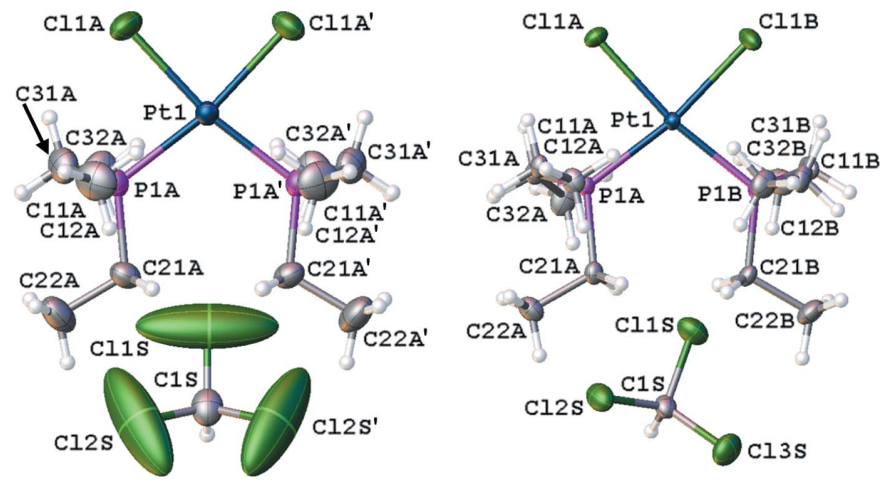

Figure 2

The molecular structure of $(1 a)$ at $220 \mathrm{~K}$ (left, the mirror plane runs through atoms Pt1, Cl $1 S$ and $\mathrm{C} 1 S)$ and $(1 b)$ at $120 \mathrm{~K}$ (right). Atomic displacement parameters are shown at $50 \%$ probability in all crystallographic figures. [Symmetry code: (') $x,-y+\frac{1}{2}, z$.] 
Upon cooling below the phase transition, the rotation of the solvent molecule ceases, with respect to the time scale of the diffraction experiment, and appears to 'lock' into place. The $\mathrm{CHCl}_{3}$ molecule is subsequently no longer symmetrical about a mirror plane, causing a reduction in the symmetry of the system. The structure of $(1 b)$ thus adopts the space group $P 2{ }_{1} 2_{1} 2_{1}$ with $Z^{\prime}=1$ at $120 \mathrm{~K}$. This transition is illustrated in Figs. 2 and 3. A whole-molecule twist, of both the complex and solvent molecules, with respect to the unit cell appears to be driven by a decrease in intermolecular distances, causing stronger $\mathrm{Cl} \cdots \mathrm{H}$ interactions. This results in movements of the ethyl 'arms', further breaking the higher-temperature symmetry, as seen from the positions of atoms $C 32 A / B$ in Fig. 2. The system reverts to the Pnma setting on returning to higher temperatures, demonstrating that the transition is fully reversible within the constraint that the temperature ramping rates are $\leq 120 \mathrm{~K} \mathrm{~h}^{-1}$.

Electron-density maps $\left(F_{\text {obs }}\right)$ through the mean plane defined by the $\mathrm{Cl}$ atoms of the chloroform molecule at the two temperatures are shown in Fig. 4, highlighting the decrease in dynamic disorder across the phase transition.

Selected bond distances and angles for $(1 a)$ and $(1 b)$ are listed in Table 1, together with data for one of the previously identified unsolvated monoclinic polymorphs, (2), at $293 \mathrm{~K}$ (space group $C c$; Otto \& Muller, 2001) for which atomic coordinates are available. The second reported unsolvated polymorph (Caldwell et al., 1977) is not included in Table 1 as no three-dimensional coordinates are available, although Otto \& Muller describe it as being isostructural with their cis$\left[\mathrm{PtCl}_{2}\left(\mathrm{AsEt}_{3}\right)_{2}\right]$ complex. The known unsolvated polymorphs differ from the title compound (1) not only by the absence of the solvent molecule but also in the relative configuration of the $\mathrm{PEt}_{3}$ groups (see Scheme).

The difference in orientation of the $\mathrm{PEt}_{3}$ ligands around the $\mathrm{Pt}-\mathrm{P}$ bonds may be better understood by considering the ethyl moiety that lies close to the $\mathrm{PtP}_{2} \mathrm{Cl}_{2}$ plane of the $\mathrm{Pt}$ atom. As in the case of the previously reported structures, there is
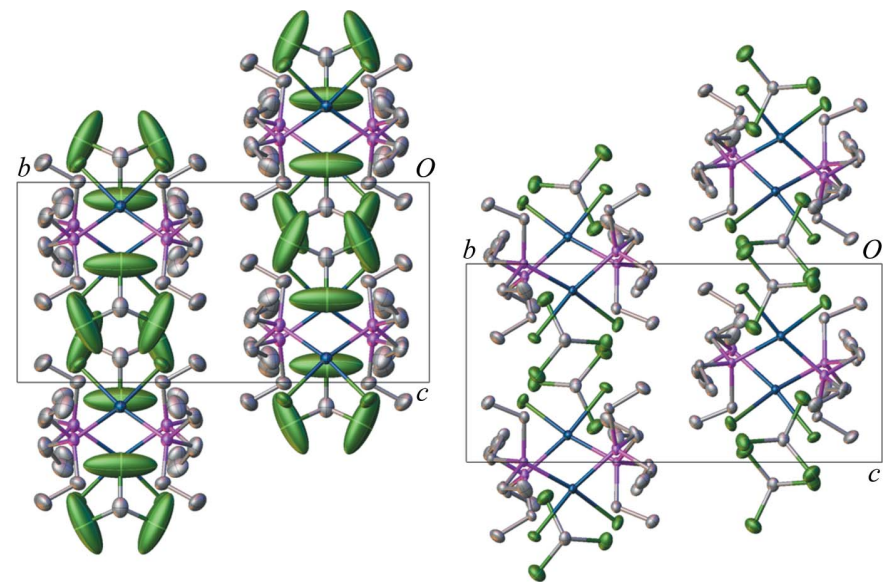

Figure 3

Projection of the crystal packing along the [100] direction of (1a) and (1b) (left and right, respectively), showing the shift in relative molecular orientations as well as the layered motif exhibited in both structures. $\mathrm{H}$ atoms have been omitted for clarity. one substituent on each $\mathrm{P}$ atom in (1) that lies very near the $\mathrm{PtP}_{2} \mathrm{Cl}_{2}$ plane. However, unlike in the previously reported structures, these in-plane substituents point towards one another, as shown in the Scheme. It may be expected that this arrangement of the ethyl groups will be somewhat sterically unfavourable, although it does give rise to an increased number of $\mathrm{C}-\mathrm{H} \cdots \mathrm{Cl}$ interactions, made possible by the presence of the $\mathrm{CHCl}_{3}$ solvent.

The packing motifs of the solvated and unsolvated structures are dominated by $\mathrm{C}-\mathrm{H} \cdots \mathrm{Cl}$ interactions. In the case of (2), the only short intermolecular interaction is $\mathrm{C} 121-$ $\mathrm{H} 12 B \cdots \mathrm{Cl} 1^{\mathrm{i}}\left[\mathrm{H} \cdots \mathrm{Cl}=2.905 \AA\right.$; symmetry code: (i) $x+\frac{1}{2}$, $\left.-y+\frac{1}{2}, z+\frac{1}{2}\right]$, which forms one-dimensional chains along the [101] direction. In contrast, $(1 a)$ and $(1 b)$ form extended hydrogen-bonding networks (Tables 2 and 3 ); (1a) forms twodimensional sheets which, upon cooling, interlink to give rise to the three-dimensional hydrogen-bonding network found in $(1 b)$, shown in Fig. 5.

The $\mathrm{Pt}-\mathrm{Cl}$ distances (Table 1) are almost identical in (1a), $(1 b)$ and (2), although the $\mathrm{Pt}-\mathrm{P}$ bond lengths show some variation and are shorter in both forms of (1). The most instructive differences between (1) and (2) lie in the bond

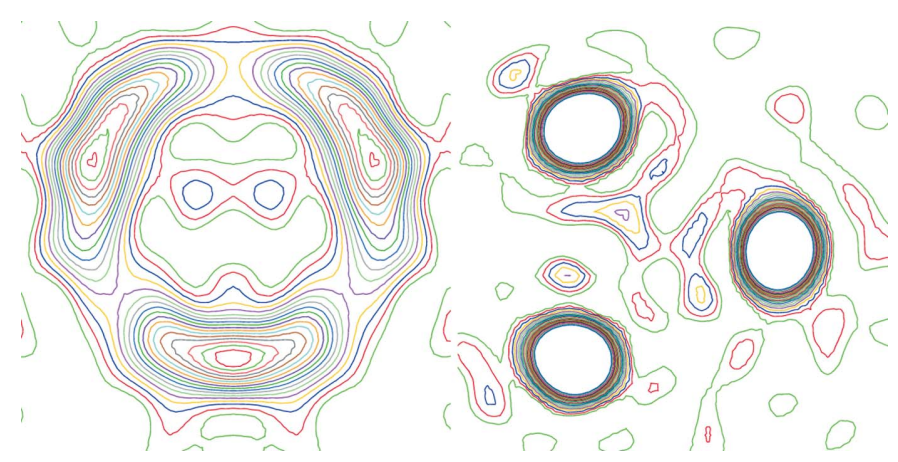

Figure 4

Electron-density maps $\left(F_{\text {obs }}\right)$ through the mean plane defined by the $\mathrm{Cl}$ atoms of the chloroform solvent molecule in the structures at $220 \mathrm{~K}$ (left) and $120 \mathrm{~K}$ (right). Contour lines are displayed at 0.5 e $\AA^{-3}$ intervals (higher contour levels have been omitted for clarity for the $120 \mathrm{~K}$ data).
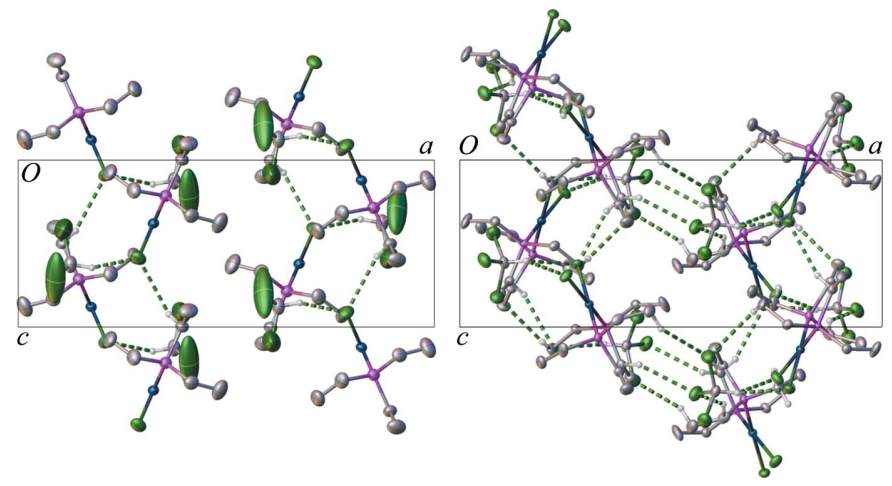

Figure 5

Hydrogen-bonding networks of $(1 a)$ at $220 \mathrm{~K}$ (left) and $(1 b)$ at $120 \mathrm{~K}$ (right). The displayed intermolecular interactions were identified using the same threshold delta function in OLEX2 (Dolomanov et al., 2009) of $1.68 \AA$ to highlight the difference between the structures either side of the phase transition. $\mathrm{H}$ atoms not involved in intermolecular contacts have been omitted for clarity. 
angles in the approximately square-planar coordination geometry. While the $\mathrm{Cl}-\mathrm{Pt}-\mathrm{Cl}$ angles are very similar, the $\mathrm{P}-\mathrm{Pt}-\mathrm{P}$ angle is over $5^{\circ}$ larger in the new polymorphs, reflecting the increased steric repulsion between the $\mathrm{PEt}_{3}$ groups. There is far less variation in the $\mathrm{Cl}-\mathrm{Pt}-\mathrm{P}$ angles found in the polymorphs of (1) (all within $1^{\circ}$ ) compared with the monoclinic form, where they differ by greater than $6^{\circ}$, a result explained by the differing steric demands on the positions of the two $\mathrm{Cl}$ atoms in these structures. These effects may arise from the difference in alignment of the ethyl substituents on the $\mathrm{PEt}_{3}$ ligands, compared with that in (2) described by Otto \& Muller (2001). The geometric parameters for $(1 a)$ and (1b) are similar to the literature data for other cis$\left[\mathrm{PtCl}_{2}\left(\mathrm{P} R_{3}\right)_{2}\right]$ complexes (Table 4).

\section{Experimental}

During the synthesis of cis-[ $\left.\mathrm{PtCl}_{2}\left(\mathrm{PCyp}_{2} \mathrm{Cl}\right)\left(\mathrm{PEt}_{3}\right)\right]$, all manipulations, including NMR sample preparation, were carried out either under an inert atmosphere of dry nitrogen or in vacuo, using standard Schlenk line or glove-box techniques. Chemicals of the best available commercial grade were used, in general without further purification. The ${ }^{31} \mathrm{P}$ NMR spectra of all phosphorus-containing starting materials were recorded, to verify that no major impurities were present. The synthesis of trans- $\left[\mathrm{PtCl}(\mu-\mathrm{Cl})\left(\mathrm{PEt}_{3}\right)\right]_{2}$ was carried out according to the literature procedure of Dillon et al. (2010). ${ }^{31} \mathrm{P}$ NMR spectra were obtained on a Varian Mercury 400 Fourier-transform spectrometer at $161.91 \mathrm{MHz}$; chemical shifts are referenced to $85 \% \mathrm{H}_{3} \mathrm{PO}_{4}$, with the high-frequency direction taken as positive.

$\mathrm{Cyp}_{2} \mathrm{PCl}(0.042 \mathrm{ml}, 0.22 \mathrm{mmol})$ was added via syringe to a solution of trans $-\left[\mathrm{PtCl}(\mu-\mathrm{Cl})\left(\mathrm{PEt}_{3}\right)\right]_{2}(0.0840 \mathrm{~g}, 0.11 \mathrm{mmol})$ in $\mathrm{CDCl}_{3}(1 \mathrm{ml})$. Formation of $c i s-\left[\mathrm{PtCl}_{2}\left(\mathrm{P}_{B} \mathrm{Cyp}{ }_{2} \mathrm{Cl}\right)\left(\mathrm{P}_{A} \mathrm{Et}_{3}\right)\right]$ was confirmed using ${ }^{31} \mathrm{P}$ NMR spectroscopy: $\delta \mathrm{P}_{A} 13.6$ p.p.m. (singlet + satellites, ${ }^{1} J_{\mathrm{Pt}-\mathrm{P}}=$ $3506 \mathrm{~Hz},{ }^{2} J_{\mathrm{P}-\mathrm{P}}=13 \mathrm{~Hz}$ ), $\delta \mathrm{P}_{B} 113.0$ p.p.m. (singlet + satellites, ${ }^{1} J_{\mathrm{Pt}-\mathrm{P}}=$ $4024 \mathrm{~Hz},{ }^{2} J_{\mathrm{P}-\mathrm{P}}=13 \mathrm{~Hz}$ ). Attempted hydrolysis of this complex resulted in ligand scrambling to afford compound (1), cis$\left[\mathrm{PtCl}_{2}\left(\mathrm{PEt}_{3}\right)_{2}\right]\left[{ }^{31} \mathrm{P}\right.$ NMR: $\delta 10.2$ p.p.m. (singlet + satellites, ${ }^{1} J_{\mathrm{Pt}-\mathrm{P}}=$ $3514 \mathrm{~Hz})]$, and also cis- $\left[\mathrm{PtCl}_{2}\left(\mathrm{PCyp}_{2} \mathrm{Cl}\right)_{2}\right]\left[{ }^{31} \mathrm{P}\right.$ NMR: $\delta 108.1$ p.p.m. (singlet + satellites, ${ }^{1} J_{\mathrm{Pt}-\mathrm{P}}=4037 \mathrm{~Hz}$ )]. Colourless crystals of (1) were obtained by slow evaporation of solvent from the reaction mixture. Crystals of (1) were also isolated from hydrolysis reactions of cis$\left[\mathrm{PtCl}_{2}\left(\mathrm{PCy}_{2} \mathrm{Cl}\right)\left(\mathrm{PEt}_{3}\right)\right]$ and cis- $\left[\mathrm{PtCl}_{2}\left(\mathrm{PCyCl}_{2}\right)\left(\mathrm{PEt}_{3}\right)\right](\mathrm{Cy}=$ cyclohexyl).

A crystal of (1) was mounted in inert oil and placed in the cold gas stream of an $\mathrm{N}_{2}$ cryostream device (Cosier \& Glazer, 1986) at $220 \mathrm{~K}$. Data were collected at this temperature before ramping at a rate of $120 \mathrm{~K} \mathrm{~h}^{-1}$ to $120 \mathrm{~K}$, where the diffraction experiment was repeated. The temperature was again ramped at $120 \mathrm{~K} \mathrm{~h}^{-1}$ to $220 \mathrm{~K}$ where a short data collection was performed to assess the reversibility of the transition.

\section{Compound (1a)}

\section{Crystal data}

\begin{tabular}{|c|c|}
\hline $\begin{array}{l}{\left[\mathrm{PtCl}_{2}\left(\mathrm{C}_{6} \mathrm{H}_{15} \mathrm{P}\right)_{2}\right] \cdot \mathrm{CHCl}_{3}} \\
M_{r}=621.66 \\
\text { Orthorhombic, } P \text { rnma } \\
a=19.0103(9) \AA \\
b=15.7378(7) \AA \\
c=7.6394(4) \AA\end{array}$ & $\begin{array}{l}V=2285.56(19) \AA^{3} \\
Z=4 \\
\text { Mo } K \alpha \text { radiation } \\
\mu=6.86 \mathrm{~mm}^{-1} \\
T=220 \mathrm{~K} \\
0.21 \times 0.20 \times 0.18 \mathrm{~mm}\end{array}$ \\
\hline
\end{tabular}

Table 1

Selected geometric parameters $\left(\AA,^{\circ}\right)$ for $(1 a),(1 b)$ and $(2)$.

\begin{tabular}{lccl}
\hline & $(1 a)$ & $(1 b)$ & $(2)$ \\
\hline $\mathrm{Pt} 1-\mathrm{Cl} 1 A$ & $2.3627(17)$ & $2.3696(10)$ & $2.364(2)$ \\
$\mathrm{Pt} 1-\mathrm{Cl} 1 B$ & & $2.3665(11)$ & $2.374(2)$ \\
$\mathrm{Pt} 1-\mathrm{P} 1 A$ & $2.2540(16)$ & $2.2524(11)$ & $2.264(2)$ \\
$\mathrm{Pt} 1-\mathrm{P} 1 B$ & & $2.2550(11)$ & $2.2616(18)$ \\
$\mathrm{P} 1 A-\mathrm{Pt} 1-\mathrm{P} 1 B^{*}$ & $104.77(9)$ & $103.89(4)$ & $98.39(7)$ \\
$\mathrm{P} 1 A-\mathrm{Pt} 1-\mathrm{Cl} 1 A$ & $84.71(6)$ & $85.18(4)$ & $84.63(9)$ \\
$\mathrm{P} 1 A-\mathrm{Pt} 1-\mathrm{Cl} 1 B$ & & $85.06(4)$ & $91.33(7)$ \\
$\mathrm{Cl} 1 A-\mathrm{Pt} 1-\mathrm{Cl} 1 B^{*}$ & $85.80(10)$ & $85.94(4)$ & $85.66(9)$ \\
\hline
\end{tabular}

Note: $(*)$ symmetry equivalent for $(1 a)$ using symmetry operation $\left(x,-y+\frac{1}{2}, z\right)$.

Table 2

Hydrogen-bond geometry $\left(\AA,^{\circ}\right)$ for $(1 a)$.

\begin{tabular}{lllll}
\hline$D-\mathrm{H} \cdots A$ & $D-\mathrm{H}$ & $\mathrm{H} \cdots A$ & $D \cdots A$ & $D-\mathrm{H} \cdots A$ \\
\hline $\mathrm{C} 21 A-\mathrm{H} 21 B \cdots \mathrm{C} 1 A^{\mathrm{i}}$ & 0.98 & 2.97 & $3.717(7)$ & 134 \\
$\mathrm{C} 31 A-\mathrm{H} 31 A \cdots \mathrm{C} 2 S^{\text {ii }}$ & 0.98 & 2.93 & $3.802(9)$ & 149 \\
$\mathrm{C} 1 S-\mathrm{H} 1 S \cdots \mathrm{Cl} 1 A^{\mathrm{iii}}$ & 0.99 & 2.70 & $3.505(10)$ & 139 \\
$\mathrm{C} 1 S-\mathrm{H} 1 S \cdots \mathrm{Cl} 1 A^{\text {iv }}$ & 0.99 & 2.70 & $3.505(10)$ & 138
\end{tabular}

Symmetry codes: (i) $x, y, z+1$; (ii) $-x+1,-y,-z+2$; (iii) $x-\frac{1}{2},-y+\frac{1}{2},-z+\frac{3}{2}$; (iv) $x-\frac{1}{2}, y,-z+\frac{3}{2}$.

\section{Data collection}

Bruker SMART CCD 1K area-detector diffractometer Absorption correction: multi-scan (SADABS; Sheldrick, 2003) $T_{\min }=0.759, T_{\max }=1.0$

Refinement

$R\left[F^{2}>2 \sigma\left(F^{2}\right)\right]=0.039$

$w R\left(F^{2}\right)=0.105$

$S=1.02$

2928 reflections

\section{Compound (1b)}

Crystal data

$\left[\mathrm{PtCl}_{2}\left(\mathrm{C}_{6} \mathrm{H}_{15} \mathrm{P}\right)_{2}\right] \cdot \mathrm{CHCl}_{3}$

$M_{r}=621.66$

Orthorhombic, $P 2_{1} 2_{1} 2_{1}$

$a=18.9529$ (9) ^

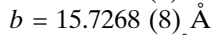

$c=7.4934$ (4) $\AA$

Data collection

Bruker SMART CCD $1 \mathrm{~K}$ area-detector diffractometer Absorption correction: multi-scan (SADABS; Sheldrick, 2003) $T_{\min }=0.757, T_{\max }=1.000$

Refinement

$R\left[F^{2}>2 \sigma\left(F^{2}\right)\right]=0.023$

$w R\left(F^{2}\right)=0.045$

$S=1.04$

5546 reflections

$\mathrm{H}$ atoms were constrained to idealized geometries, riding on their associated C atoms, with fixed $\mathrm{C}-\mathrm{H}$ distances $(0.97-1.00 \AA$ ) and with $U_{\text {iso }}(\mathrm{H})=1.2 U_{\text {eq }}(\mathrm{C})$ [or $1.5 U_{\text {eq }}(\mathrm{C})$ for methyl $\mathrm{H}$ atoms]. On trans- 
Table 3

Hydrogen-bond geometry $\left(\AA,^{\circ}\right)$ for $(1 b)$.

\begin{tabular}{lllll}
\hline$D-\mathrm{H} \cdots A$ & $D-\mathrm{H}$ & $\mathrm{H} \cdots A$ & $D \cdots A$ & $D-\mathrm{H} \cdots A$ \\
\hline $\mathrm{C} 1 S-\mathrm{H} 1 S \cdots \mathrm{Cl} 1 A$ & 1.00 & 2.67 & $3.482(4)$ & 138 \\
$\mathrm{C} 1 S-\mathrm{H} 1 S \cdots \mathrm{Cl} 1 B$ & 1.00 & 2.63 & $3.466(4)$ & 141 \\
$\mathrm{C} 21 A-\mathrm{H} 21 B \cdots \mathrm{Cl} 1 A^{\mathrm{i}}$ & 0.99 & 2.72 & $3.606(5)$ & 149 \\
$\mathrm{C} 21 A-\mathrm{H} 21 A \cdots \mathrm{Cl} 2 S^{\mathrm{ii}}$ & 0.99 & 2.85 & $3.601(5)$ & 133 \\
$\mathrm{C} 12 A-\mathrm{H} 12 A \cdots \mathrm{Cl} 1 S$ & 0.98 & 2.97 & $3.727(5)$ & 135 \\
$\mathrm{C} 32 B-\mathrm{H} 32 F \cdots \mathrm{Cl} 1 S^{\mathrm{ii}}$ & 0.98 & 2.93 & $3.797(5)$ & 148 \\
$\mathrm{C} 31 B-\mathrm{H} 31 D \cdots \mathrm{C} 2 S^{\mathrm{iii}}$ & 0.99 & 2.97 & $3.817(4)$ & 145
\end{tabular}

Symmetry codes: (i) $x, y, z+1$; (ii) $x-\frac{1}{2},-y+\frac{1}{2},-z+1$; (iii) $-x+\frac{1}{2},-y, z+\frac{1}{2}$.

\section{Table 4}

Selected geometric parameters $\left(\AA{ }^{\circ}\right)$ for $c i s-\left[\mathrm{PtCl}_{2}\left(\mathrm{PR}_{3}\right)_{2}\right]$ complexes.

\begin{tabular}{|c|c|c|c|c|c|}
\hline Compound & $\mathrm{Pt}-\mathrm{P}$ & $\mathrm{Pt}-\mathrm{Cl}$ & $\mathrm{P}-\mathrm{Pt}-\mathrm{P}$ & $\mathrm{Cl}-\mathrm{P}-\mathrm{Cl}$ & Reference \\
\hline \multirow[t]{2}{*}{$\mathrm{PMe}_{3}$} & $2.256(8)$ & $2.364(8)$ & $96.2(4)$ & $87.47(3)$ & $a$ \\
\hline & $2.239(6)$ & $2.388(8)$ & & & \\
\hline \multirow[t]{2}{*}{$\mathrm{P}^{t} \mathrm{Bu}_{3}$} & $2.321(5)$ & $2.367(6)$ & $107.3(4)$ & $84.2(3)$ & $b$ \\
\hline & $2.344(5)$ & $2.349(6)$ & & & \\
\hline \multirow[t]{2}{*}{$\mathrm{PMe}_{2} \mathrm{Ph}$} & $2.242(1)$ & $2.359(1)$ & $94.80(4)$ & $86.55(5)$ & $c$ \\
\hline & $2.245(1)$ & $2.355(1)$ & & & \\
\hline \multirow[t]{2}{*}{$\mathrm{PCy}_{3}$} & $2.299(4)$ & $*$ & 107.6 & 82.1 & $d$ \\
\hline & $2.289(3)$ & $*$ & & & \\
\hline \multirow[t]{2}{*}{$\mathrm{PEtPh}_{2}$} & $2.2633(9)$ & $2.3458(9)$ & $100.23(3)$ & $85.30(3)$ & $e$ \\
\hline & $2.2517(9)$ & $2.3618(9)$ & & & \\
\hline \multirow[t]{2}{*}{$\mathrm{PEt}_{2} \mathrm{Ph}$} & $2.2515(12)$ & $2.3505(12)$ & $94.43(4)$ & $85.77(5)$ & $f$ \\
\hline & $2.2544(13)$ & $2.3619(12)$ & & & \\
\hline
\end{tabular}

Note: (*) no three-dimensional coordinates available. References: (a) Messmer et al. (1967); (b) Porzio et al. (1980); (c) Attia et al. (1987); (d) Cameron et al. (1989); (e) Domanska-Babul, Chojnacki et al. (2007); ( $f$ ) Domańska-Babul, Pikies et al. (2007).

forming to the low-temperature phase, the structure refinement indicated the presence of an inversion twin. The major twin fraction refined to 0.486 (5) and was subsequently fixed at 0.5 . There are high values of the maximum and minimum residual electron density in (1a). These peaks (2.19 and $-1.98 \mathrm{e} \mathrm{A}^{-3}$, respectively) are located between the $\mathrm{Cl}$ atoms of the chloroform solvent molecule and reflect the distribution of electron density shown in Fig. 4 (left) caused by the dynamic disorder of this fragment. These residual peaks serve to reinforce the conclusions drawn regarding the disorder and the phase transition.
For both compounds, data collection: SMART (Bruker, 1999); cell refinement: SAINT (Bruker, 2003); data reduction: SAINT; program(s) used to solve structure: SHELXS97 (Sheldrick, 2008); program(s) used to refine structure: SHELXL97 (Sheldrick, 2008); molecular graphics: OLEX2 (Dolomanov et al., 2009); software used to prepare material for publication: $O L E X 2$.

We thank the EPSRC (UK) for research grant No. EP/ C536436/1 (MRP) and for a research studentship (HJS), the Maria da Graça Memorial Fund/Chemistry Department, Durham University (PKM), for financial support, and Johnson Matthey plc for the loan of precious metal compounds.

Supplementary data for this paper are available from the IUCr electronic archives (Reference: LN3146). Services for accessing these data are described at the back of the journal.

\section{References}

Attia, W. M., Balducci, G. \& Calligaris, M. (1987). Acta Cryst. C43, 1053-1055. Bruker (1999). SMART. Version 5.049. Bruker AXS Inc., Madison, Wisconsin, USA.

Bruker (2003). SAINT. Version 6.45A. Bruker AXS Inc., Madison, Wisconsin, USA.

Caldwell, A. N., Manojlovic-Muir, L., Muir, K. W. \& Solomun, T. (1977). Eur. Crystallogr. Meet., Oxford, 30 August-3 September, Abstract PI.57, p. 210.

Cameron, T. S., Clark, H. C., Linden, A. \& Nicholaas, A. M. (1989). Inorg. Chim. Acta, 162, 9-10.

Cornet, S. M. M., Dillon, K. B., Dyer, P. W., Goeta, A. E., Howard, J. A. K., Monks, P. K., Shepherd, H. J., Thompson, A. L. \& Wright, W. R. H. (2011). In preparation.

Cosier, J. \& Glazer, A. M. (1986). J. Appl. Cryst. 19, 105-107.

Dillon, K. B., Goeta, A. E., Monks, P. K. \& Shepherd, H. J. (2010). Polyhedron, 29, 606-612.

Dolomanov, O. V., Bourhis, L. J., Gildea, R. J., Howard, J. A. K. \& Puschmann, H. (2009). J. Appl. Cryst. 42, 339-341.

Domanska-Babul, W., Chojnacki, J. \& Pikies, J. (2007). Acta Cryst. E63, m1956. Domańska-Babul, W., Pikies, J. \& Chojnacki, J. (2007). Acta Cryst. E63, m2583. Messmer, G. G., Amma, E. L. \& Ibers, J. A. (1967). Inorg. Chem. 6, 725-730. Otto, S. \& Muller, A. J. (2001). Acta Cryst. C57, 1405-1407.

Porzio, W., Musco, A. \& Immirzi, A. (1980). Inorg. Chem. 19, 2537-2540.

Sheldrick, G. M. (2003). SADABS. Version 2.10. University of Göttingen, Germany.

Sheldrick, G. M. (2008). Acta Cryst. A64, 112-122. 